\title{
Case-control study of factors associated with chronic Chagas heart disease in patients over 50 years of age
}

\author{
Silvana de Araújo Silva ${ }^{+}$, Eliane Dias Gontijo, Carlos Faria Santos Amaral \\ Faculdade de Medicina, Universidade Federal de Minas Gerais, Avenida Alfredo Balena, 190, sala 825, Santa Efigênia, $30130-100$ \\ Belo Horizonte, MG, Brasil
}

A case-control study on chronic Chagas heart disease (CCHD) was carried out between 1997 and 2005. Ninety patients over 50 years of age were examined for factors related to (CCHD). Fourty-six patients (51.1\%) with Chagas heart disease (anomalous ECG) were assigned to the case group and 44 (48.9\%) were included in the control group as carriers of undetermined forms of chronic disease. Social, demographic (age, gender, skin color, area of origin), epidemiological (permanence within an endemic zone, family history of Chagas heart disease or sudden death, physical strain, alcoholism, and smoking), and clinical (systemic hypertension) variables were analyzed. The data set was assessed through single-variable and multivariate analysis. The two factors independently associated with heart disease were age - presence of heart disease being three times higher in patients over 60 years of age (odds ratio, OR: 2.89; confidence interval of 95\%: 1.09-7.61) - and family history of Chagas heart disease (OR: 2.833, CI 95\%: 1.11-7.23). Systemic hypertension and gender did not prove to hold any association with heart disease, as neither did skin color, but this variable showed low statistical power due to reduced sample size.

Key words: Chagas disease - case-control study - risk factors - heart diseases - epidemiology

Chagas disease is a relevant health problem in Latin America, as it affects the lives of 13 million people in the continent (WHO 2005a). Brazil alone accounts for approximately 3.5 million patients, $30 \%$ of which have heart involvement. Half the cases are categorized as carriers of undetermined forms of chronic disease. Among the most peculiar characteristics of chronic Chagas heart disease (CCHD) are the frequent and complex episodes of cardiac arrhythmia in combination with conduction disorders, and the remarkably high incidence of sudden death and systemic thromboembolism (MS 2005).

A few studies have looked at patients over 50 years of age with Chagas disease (Netto et al. 1970, Carneiro \& Rezende 1982, Carvalho Filho et al. 1985, Silva 1992, Rocha et al. 2003), in spite of the relatively strong aging process the Brazilian population is going through. Today, an estimated $9 \%$ of the country's population is 65 or older (IBGE 2000).

Significant controversy still exists on the factors related to the evolution of the undetermined form of chronic Chagas disease, as some patients develop the most severe features of the disease while others remain symptom-free for their entire lives. Parasite-related factors such as biologic variability and the genetics of Trypanosoma cruzi (Macedo et al. 2004), as well as factors related to the host such as gender, age, physical strain, skin color, exposure to reinfection, and family history for cardiovascular disease (Baruffa et al. 1987, Zicker 1990,

${ }^{+}$Corresponding author: silvanadearaujosilva@hotmail.com Received 30 May 2007

Accepted 22 October 2007
Pereira-Barretto et al. 1993, Gontijo et al. 1996) have been targeted, although mostly by cross-sectional studies, which are not the most appropriate epidemiological study designs to identify factors related to outcomes.

This study aims to identify the factors associated with CCHD in patients over 50 years of age.

\section{PATIENTS AND METHODS}

This case-control study covered Chagas disease patients living in the Metropolitan Area of Belo Horizonte seen at the Chagas disease ambulatory of the University Hospital, Universidade Federal de Minas Gerais, between 1997 and 2005. The selected patients were 50 years old or older, and had to meet the following inclusion criteria: two positive serological tests using different techniques, undergo for one year all the tests included in the protocol - clinical examination, two -view chest X-rays, 12-lead electrocardiogram (ECG), Doppler echocardiography, esophagogram and opaque enema. Patients with other heart conditions (ischemic, congenital, and valvar) referred to or investigated by clinical/additional examination were excluded.

Data collection tools - patients answered a structured questionnaire during their visits to the ambulatory. All responses were entered into Microsoft Access.

Additional workups were used to categorize patients into clinical forms of the disease as follows:

12-lead ECG: Readings were done based on the criteria set by Lazzari et al. (1998). The usual changes of chronic Chagas heart disease were considered, namely: complete right bundle-branch block (complete RBBB) with or without anterior-superior division block (ASDB), ventricular extrasystole (VES), sinus bradycardia with heartbeat at less than $40 \mathrm{bpm}$, second-degree atrioventricular block (AVB), primary $\mathrm{T}$ wave alterations, presence of electrically inactive areas, sinoatrial node 
dysfunction, unsustained ventricular tachycardia, atrial fibrillation, complete atrioventricular block, and left bundle-branch block. When two or more non-specific changes were found - sinus bradycardia with heartbeat $>$ $40 \mathrm{bpm}$, low voltage, incomplete right bundle-branch block (incomplete RBBB), ASDB, first degree AVB, nonspecific alterations of ST segment and T wave alterations (MS 2005) - the ECG was classified as abnormal.

Chest radiological study: Patients with a cardiothoracic ratio (CTR) (Magalhães 1980) > 0.50 were considered to have abnormal results.

Doppler echocardiogram: Ejection fraction (EF) was evaluated on mode $\mathrm{M}$ based on the calculation procedure proposed by Teichholz et al. (1976). Segmentar wall motion abnormality was defined by the presence of akinesia, hypokinesia or dyskinesia in a limited region. Patients with either anomalous ventricular function or segmentar contractility alteration including apical aneurysm were considered to have abnormal results. Systolic dysfunction was assumed to be present when $\mathrm{EF}<56 \%$. Left ventricle diastolic function was categorized as altered when dysfunction was greater than degree I (altered left ventricle diastolic relaxation), as this manifestation, when isolated, can be associated with aging (Affiune 2001).

Esophagogram: The classification proposed by Rezende et al. (1960) was adopted.

Opaque enema: It was performed according to Ximenes (1984) and classified as abnormal when megacolon was present.

All tests were blindly interpreted in relation to the clinical form of the disease.

Patients included in the case group were those with $\mathrm{CCHD}$, i.e., with anomalous electrocardiograms (MS 2005). These patients were divided into three subgroups depending on the echocardiographic parameters: IIa, normal echocardiogram; IIb, abnormal echocardiogram, but with $\mathrm{EF}>45 \%$, and IIc, abnormal echocardiogram, with $\mathrm{EF} \leq 45 \%$. Patients in the control group had the undetermined form of chronic disease - symptom-free at rest ECG - and heart, esophagus, and colon looking normal on X-ray images (MS 2005).

The study considered the clinical form of disease (undetermined or CCHD) to be variable-dependent and took the following explanatory variables into account: social and demographic data such as age, gender, skin color (white, black and mixed), and patients' area of origin; epidemiological data as time spent by the patient in the endemic zone (in years), family history of Chagas heart disease or sudden death in individuals younger than 40 years of age, intensity of on-the-job physical strain, and information on alcohol consumption (grams of ethanol per week) and smoking (year-packs); and the clinical variable (systemic hypertension, defined as disease referred to by the patient, use of anti-hypertension medication or blood pressure $\geq 140 / 90 \mathrm{mmHg}$, based on the SBC 2004).

Statistical analysis - Data statistical analysis involved frequency distribution, measurements of central tendency, verification of the association between explanatory variables and response, and the use of Pearson's chi-square test or Fisher's exact test for categorical variables. The statistical decision was made based on the descriptive value of the test ( $p$ value). For continuous variables the likelihood-ratio test was used in the logistic regression model that follows the $\chi^{2}$ distribution to detect differences in the averages between the case and control groups. An odds ratio (OR) with a confidence interval of 95\% (CI 95\%) and significance level of 0.05 was used in the multivariate analysis to determine the independent effect of associations. The models tested included the variables that carried with them known epidemiological relevance as described in previous studies in the literature or $\mathrm{p}$ value $<0.10$ in the single-variable analysis. Modeling was done in successive stages, in compliance with adjustment principles and avoiding the occurrence of colinearity. The models were assessed using Wald's and Hosmer-Lemeshow tests. Software packages MINITAB for Windows 14.10, nQuery Advisor 4.0 and SPSS 10 were used.

This study was approved by the Research Ethics Committee of the Federal University of Minas Gerais (ETIC 358/04).

\section{RESULTS}

The study included 90 Chagas patients, 46 (51.1\%) of which in the case. These patients were further categorized into groups IIa (30 or $65.2 \%$ ), IIb (11 or $23.9 \%)$ and IIc (5 or $10.9 \%)$. The remaining 44 (48.9\%) were assigned to the control group. Twenty-two patients had alterations on the esophagogram, while fourteen had megacolon as verified in the opaque enema, thus characterizing the mixed manifestation of Chagas disease. Some patients presented alterations on both tests.

Patients were predominantly females $(56.7 \%)$, with ages between 50 and 77 years, and average age of 59 (STD: 7.15) and median of 57.5 for case group members, and 56 (STD: 4.98) and 55.0 years respectively for control group members. Most were non-whites (65.5\%) from endemic zones (90\%), where they had lived for 18 years on average, now living in the Belo Horizonte Metropolitan Area (94.5\%). In terms of physical strain, $57.8 \%$ of patients reported levels from moderate to severe on-the-job strain. Most denied current or previous use of alcohol $(52 \%)$ or tobacco $(66 \%)$.

All tests (ECG, chest X-ray, esophagogram and opaque enema) were normal for patients classified under the undetermined form of chronic disease. Concurrently, all Doppler echocardiograms of undetermined chronic disease patients were normal based on the criteria adopted.

All ECG results for patients on group II (CCHD) presented at least one alteration consistent with Chagas disease or two or more non-specific alterations. Among these alterations, the most frequently found on the ECG were RBBB alone or in conjunction with ASDB (37.8\%), ST segment alterations (17.7\%), first degree AVB (14.4\%), sinus bradycardia (10\%) and VES (6.7\%). Sixteen $(17.7 \%)$ echocardiograms presented alterations, the most frequent being anomalous segmental contraction (75\%), followed by EF alterations $(62.5 \%)$. The image of apical aneurysm was observed in four tests; $11 \%$ of patients had $\mathrm{EF} \leq 45 \%$. 
Chest X-rays showed alterations, i.e., cardiothoracic ratio $>0.50$ on $12.4 \%$ of the patients.

Single-variable analysis showed a significant association between age and Chagas heart disease. The binary logistic regression model (Table I) pointed that for each additional year of age patients have 1.087 more chance of progressing to heart disease. Patients were further divided into two age groups, the first featuring those with 50-59 years-old and the second with patients aged 60 or more. The chance of evolving to heart disease was about three times greater in the older group (OR: 2.89, CI 95\%: 1.09-7.61). There was no significant difference between groups in terms of skin color and gender, even after categorization, in spite of the marked statistical power of the sample to the last variable (85\%). No difference was found between groups in relation to epidemiological variables (Table I), except for family history of Chagas heart disease (Table II), where OR was almost three times greater among case group patients (OR: 2.833, CI 95\%: 1.11-7.23).
Systemic hypertension was similarly distributed between groups $(p=0.906)$. Single binary regression analysis done with each of the explanatory variables excluded such variable as a possible factor of confusion.

The modeling process was initiated with the variables selected from the single-variable analysis. The final model chosen for multivariate analysis (Table III) was the one that included variables 'family history of Chagas heart disease' and 'categorized age' divided into two groups: one with patients ranging between 50 and 59 years-old and another with patients aged 60 or older, proven to be statistically adequate (Hosmer-Lemeshow test: $\mathrm{p}=0.788)$. The statistical power of the logistic regression was $80 \%$.

The calculation of the statistical power for non-significant variables, although epidemiologically relevant such as family history of sudden death $(29 \%)$ and skin color $(43 \%)$, indicated that the lack of association may have occurred due to the size of the sample.

TABLE I

Statistical analysis of social, demographic and epidemiological explanatory variables for patients in the case and control groups, examined at the Chagas disease ambulatory, University Hospital, Universidade Federal de Minas Gerais, from 1997 to 2005

\begin{tabular}{|c|c|c|c|c|c|}
\hline Variable & Case group & Control group & $\mathrm{p}$ value & Odds ratio & CI $(95 \%)$ \\
\hline Age (years) & 59.07 & 55.97 & 0.024 & 1.087 & $(1.011 ; 1.169)$ \\
\hline \multicolumn{6}{|l|}{ Gender } \\
\hline Male & $21(23.3 \%)$ & $18(20.0 \%)$ & \multirow[t]{2}{*}{0.650} & & \\
\hline Female & $25(27.8 \%)$ & $26(28.9 \%)$ & & & \\
\hline \multicolumn{6}{|c|}{ Area of origin in endemic zone } \\
\hline Yes & $42(46.7 \%)$ & $39(43.3 \%)$ & \multirow[t]{2}{*}{0.674} & & \\
\hline No & $4(4.4 \%)$ & $5(5.6 \%)$ & & & \\
\hline \multicolumn{6}{|l|}{ Time of residence in } \\
\hline \multicolumn{6}{|l|}{ Skin color } \\
\hline White & $15(16.7 \%)$ & $16(17.8 \%)$ & \multicolumn{3}{|l|}{0.156} \\
\hline Mixed & $21(23.3 \%)$ & $25(27.8 \%)$ & \multicolumn{3}{|l|}{0.814} \\
\hline Black & $10(11.1 \%)$ & $3(3.3 \%)$ & \multicolumn{3}{|l|}{0.091} \\
\hline \multicolumn{6}{|l|}{ Categorized ethnicity } \\
\hline Black & $10(11.1 \%)$ & $3(3.3 \%)$ & \multirow[t]{2}{*}{0.056} & & \\
\hline Others & $36(40.0 \%)$ & $41(45.6 \%)$ & & & \\
\hline \multicolumn{6}{|l|}{ Use of alcohol } \\
\hline Never & $24(26.7 \%)$ & $23(25.6 \%)$ & 0.754 & & \\
\hline Yes & $13(14.4 \%)$ & $10(11.1 \%)$ & 0.668 & & \\
\hline Former drinker & $9(10.0 \%)$ & $11(12.2 \%)$ & 0.452 & & \\
\hline $\begin{array}{l}\text { Weekly ethanol } \\
\text { consumption (grams) }\end{array}$ & 85.7 & 560 & 0.246 & & \\
\hline \multicolumn{6}{|l|}{ Smoking } \\
\hline No & $30(33.3 \%)$ & $29(32.2 \%)$ & 0.866 & & \\
\hline Yes & $9(10.0 \%)$ & $7(7.8 \%)$ & 0.702 & & \\
\hline Former smoker & $7(7.8 \%)$ & $8(8.9 \%)$ & 0.773 & & \\
\hline \multicolumn{6}{|l|}{ Years of smoking / } \\
\hline
\end{tabular}


TABLE II

Statistical analysis of epidemiological variables for case and control groups of patients examined at the Chagas disease ambulatory, University Hospital, Universidade Federal de Minas Gerais, from 1997 to 2005

\begin{tabular}{|c|c|c|c|c|c|}
\hline Variable & Case group & Control group & $\mathrm{p}$ value & Odds ratio & CI $(95 \%)$ \\
\hline \multicolumn{6}{|c|}{ Family history of Chagas heart disease } \\
\hline $\begin{array}{l}\text { Yes } \\
\text { No }\end{array}$ & $\begin{array}{l}23(27.7 \%) \\
20(24.1 \%)\end{array}$ & $\begin{array}{l}12(14.5 \%) \\
28(33.7 \%)\end{array}$ & $\mathbf{0 . 0 3 2}$ & 2.683 & $(1.087 ; 6.623)$ \\
\hline
\end{tabular}

Family history of sudden death of relatives under 40 years of age

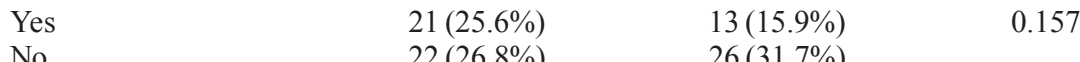

No $22(26.8 \%) \quad 26(31.7 \%)$

Intensity of on-the-job physical strain - current occupation

$\begin{array}{lccc}\text { Mild } & 8(8.9 \%) & 6(6.7 \%) & 0.899 \\ \text { Moderate } & 26(28.9 \%) & 26(28.9 \%) & 0.636 \\ \text { Severe } & 12(13.3 \%) & 12(13.3 \%) & 0.671 \\ \text { Mild+Moderate } & 34(37.8 \%) & 32(35.6 \%) & 0.899 \\ \text { Severe } & 12(13.3 \%) & 12(13.3 \%) & \\ \text { Intensity of on-the-job physical strain-previous occupation } & \\ \text { Mild } & 1(1.1 \%) & 3(3.3 \%) & 0.330 \\ \text { Moderate } & 23(25.6 \%) & 15(16.7 \%) & 0.204 \\ \text { Severe } & 9(10.0 \%) & 12(13.3 \%) & 0.513 \\ \text { Extreme } & 6(6.7) & 3(3.3 \%) & 0.186 \\ \text { Mild+Moderate } & 24(33.3 \%) & 18(25 \%) & 0.549 \\ \text { Severe+Extreme } & 15(20.8 \%) & 15(20.8 \%) & \\ & & \end{array}$

TABLE III

Final model for multivariate analysis of the case-control study conducted with patients examined at the Chagas disease ambulatory, University Hospital, Universidade Federal de Minas Gerais, from 1997 to 2005

\begin{tabular}{|c|c|c|c|c|c|c|}
\hline Variables & Case & Control & Gross OR & Adjusted OR & CI 95\% & Wald \\
\hline FH heart disease & 23 & 12 & 2.683 & 2.565 & $(1.015-6.484)$ & 3.962 \\
\hline Categorized age & 20 & 28 & 2.890 & 2.938 & $(1.035-8.338)$ & 4.100 \\
\hline
\end{tabular}

OR: odds ratio; $\mathrm{Cl}$ 95\%: confidence interval of $95 \%$.

\section{DISCUSSION}

Several studies have investigated possible risk factors for the evolution of undetermined form of chronic disease into Chagas heart disease. Among them are male gender (Zicker 1990, Pereira-Barretto et al. 1993), age (Zicker 1990), physical strain (Zicker 1990), exposure to reinfection (Macedo 1973), black skin color (Baruffa et al. 1987), and family history of cardiovascular disease (Zicker 1990, Gontijo et al. 1996). Most of these studies are cross-sectional, and the most adequate approach to investigate causative factors is either case-control or cohort-based.

Few papers in the literature compared demographic traits of Chagas and non-Chagas patients, most of which published quite some time ago without multivariate analysis to properly manage confusion factors. Baruffa et al. (1987) analyzed the pattern of ECG changes in 150 black individuals from rural areas of southern Brazil, and compared them to those of 150 whites of similar age and gender distribution living in the same area. The mean age of their study group was 39.2 years (9-78 years), and $62 \%$ were women. Eighty-four of the 150 showed positive serological response to infection by $T$. cruzi. The prevalence of ECG changes was significantly higher among blacks, irrespective of their serological status. The increased prevalence and severity of ECG changes among blacks might be attributed to various factors, including: lower income level and consequent harsher working conditions, poorer housing quality and inadequate eating habits. In addition, the increased levels of high blood pressure found among the black individuals might be associated with possible racial factors, in association with increased likelihood of myocardial lesions.

Zicker (1990), in a case-control study comprising 6,222 urban workers, assessed risk factors for heart disease by comparing Chagas patients with and without heart disease to non-Chagas individuals. No difference was found between infected and non-infected subjects in relation to average age, gender, and hypertension. Physical activity score, heart disease and sudden death were more often reported by seropositive individuals. 
Gontijo et al. (1996) looked at subjects seen in an outpatient setting and could not see differences between Chagas and non-Chagas groups in terms of skin color and hypertension. Occupations characterized by strenuous physical effort, family history of heart disease (OR: 1.55, CI 95\%: 1.06-2.25), and reports of sudden death in relatives younger than 40 years of age (OR: 2.66, CI 95\%: 1.79- 3.96) were more prevalent among Chagas patients.

In the present study we tried to minimize bias by using standardized criteria to set apart Case and Control group patients (MS 2005), and checking the comparability between groups formed in their majority by symptom-free Chagas patients referred to the ambulatory by blood banks for serologic confirmation. Group homogeneity in relation to origin within endemic areas and current place of residence outside endemic areas supports findings in the literature (Gontijo et al. 1996). Published studies point to vectorial transmission as a major pathway to contracting disease 20 years ago, stressing the discrimination to which seropositive patients were subject and their history of adversity and attempts to find better opportunities in large metropolitan areas.

The 50-77 age group also contributed to the homogeneity of the population analyzed as, according to Chaimowicz (1997), the impact of present comorbidity factors is intensified starting at 80 years of age.

The distribution of the various clinical forms of disease was balanced between groups. The lower levels of heart involvement found in the sample can be explained by the profile of outpatient subjects included in the study and the fact that the functional and organic damage caused by Chagas heart disease is the main determining factor for sudden death, which often takes place during the most productive stages of life, before advanced age is reached (Porto et al. 1985). Therefore, patients over 50 may have been naturally selected among heart disease survivors, often presenting less severe conditions and better prognosis.

Heart disease prevalence is generally the same for both genders and groups of different skin color. In older groups, prevalence tends to be higher among females, as mortality is higher among males. Prevalence rates are always higher among poorer, rural populations, in which higher illiteracy rates and precarious housing are found (Coura 1966). Kloetzel and Dias (1968) also demonstrated increased mortality rates among patients under 50 when compared to those between the ages of 50 and 60 in the beginning of the observation period.

A longitudinal study carried out in Bambuí, Brazil, compared the evolution of 885 young Chagas patients under the undetermined form of chronic disease to that of 911 Chagas patients with ECG alterations present since the beginning of the 10-year follow-up period. Survival rates were higher among the first group (97.4\%) when compared to the second (61.3\%) (Forichon 1974).

The most frequently found changes on the ECG were intraventricular conduction disorders and alterations in the ST segment, both in agreement with the literature (Macedo 1993, Rassi Jr 2003, Oliveira-Marques 2004). Netto et al. (1970), studying elderly patients, confirmed right bundle-branch block as the most frequently found change in the infected group. The identification of $11 \%$ of patients in subgroup II C (those with $\mathrm{EF} \leq 45 \%$ and thus with more severe forms of heart disease and worse prognosis) points to the need for periodic follow-up, including all workup and treatment required to properly approach complex arrhythmia and heart failure cases.

Age displayed significant differences between groups, mainly after categorization ( $>60$ years), supporting findings present in the literature (Zicker 1990). The threefold risk of patients older than 60 presenting heart disease when compared to the 50-59 years of age group characterizes age as an important factor associated with Chagas heart disease. This finding seems to be rather plausible, as the yearly conversion rate from undetermined form of disease to chronic Chagas heart disease, although low, is closely related to time. Once the population is aging, health authorities should pay closer attention and invest in improving access to health services the skills of health care workers in contact with patients with Chagas heart disease, and recognizing the clinical differences inherent to older populations. There still is considerable misinformation about the elderly and the peculiarities and challenges of aging populations and their impact on public health in our social context (WHO 2005b).

The study was statistically powerful enough (85\%) to assert that gender is not a risk factor for Chagas heart disease, a conflicting finding when compared to other studies (Zicker 1990, Pereira-Barretto et al. 1993). Black skin color never proved to be significant, not even when categorized, probably due to the sample size, revealing statistical power of only $43 \%$ for this variable.

The similarity among groups for the variables alcoholism and smoking may be ascribed to the profile of blood donors, the typical client of the ambulatory, mostly women, with well-known lower prevalence for these habits due to differences in behavior dictated by Brazilian culture and tradition (Rouquayrol 1993).

Variable 'family history of Chagas heart disease' as a factor associated with chronic Chagas heart disease confirms data published in the literature (Zicker 1990, Gontijo et al. 1996), and emphasizes the relevance of developing a differentiated approach for patients with family history of disease. Management strategies must include frequent follow-up and early diagnosis and treatment, and should recruit the therapeutic arsenal currently available for heart failure to reduce mortality and improve patients' quality of life. The health care team must provide for integral and multidisciplinary care, not limiting its action to a biologicist approach (Uchoa et al. 2002).

Physical strain, both in previous and current jobs, did not show any significant difference between case and control groups even after categorization, as found by Zicker (1990). These observations suggest that the determining factors for chronic Chagas heart disease are not external to individuals or dependent on the environment, but rather that they arise mainly from the relationship between host and parasite, possibly going through a process that ranges from exposure to reinfection (Macedo 1973, Davila et al. 1987), a common event among those living in endemic areas. 
Systemic hypertension is a severe, highly prevalent condition in the clinical setting, compromising mainly elderly individuals. Its contribution to patient outcome as a risk factor for Chagas heart disease was therefore assessed. Previous publications have shown that systemic hypertension is the most frequently present cardiovascular condition among Chagas patients (Ianni et al. 1998), and that its prevalence is greater in patients with age $\geq 50$, supporting the existence of an additive character between both illnesses (Guariento et al. 1993). This study showed that the presence of this comorbidity factor is not linked to development of Chagas heart disease and does not produce a confusion factor.

In conclusion, the present case-control study showed that factors significantly associated with chronic Chagas heart disease are age and family history of Chagas heart disease. Gender was not confirmed as a factor related to the disease, and had a high statistical power within the sample. Although it has been considered a classical factor associated with Chagas heart disease, skin color did not pose significant differences between groups, probably due to its reduced statistical power.

The findings mentioned here are relevant for the individual care plans devised for elderly Chagas patients, including projects to promote health, access to centers of higher technological complexity and welfare services. The vulnerability of elderly Chagas patients calls for public policies that take the aging of the population into account - a reality we are already faced with in Brazil, and strategies to address comorbidity factors.

\section{REFERENCE}

Affiune A 2001. Envelhecimento cardiovascular. In Freitas EV, Py L, Neri AL, Cançado FAX, Gorzoni ML, Rocha SM, Tratado de Geriatria e Gerontologia, Guanabara Koogan, Rio de Janeiro, p. 228-232.

Baruffa G, Alcantara Filho A, De Aquino Neto JO 1987. Estudo pareado da cardiopatia chagásica no Rio Grande do Sul, Brasil. Comportamento das alterações eletrocardiográficas em função da cor. Mem Inst Oswaldo Cruz 82: 399-406.

Carneiro O, Rezende JM 1982. Doença de Chagas e longevidade. Arq Bras Cardiol 38 (Suppl. V): 381- 384.

Carvalho Filho ET, Figueira JL, Pasini U, Forti NA, Curiati JAE, Ferreira MLM, Serro Azul LG 1985. Aspectos da Doença de Chagas no idoso. Arq Bras Cardiol 45: 102 -107.

Chaimowicz F 1997. A saúde dos idosos brasileiros às vésperas do século XXI: problemas, projeções e alternativas. Rev. Saude Públ 31: 184 -200.

Coura JR 1966. Contribuição ao estudo da doença de Chagas no Estado da Guanabara. Rev Bras Malariol D Trop 18: 9-98.

Davila H, Beloscar JS, Bottasso OA, Morini JC 1987. Alteraciones electrocardiograficas en individuos infectados con Trypanosoma cruzi con distinto tiempo de residencia en areas de alta endemicidad. Medicina, B Aires 47: 154-158.

Forichon E 1974. Contribuition aux estimations de morbidité et de mortalité dans la maladie de Chagas, Thesis, Toulouse, France, Paul-Sabatier, $47 \mathrm{pp}$.

IBGE - Instituto Brasileiro de Geografia e Estatística 2000 [homepage on the Internet]. Perfil dos idosos responsáveis pelos domicílios no Brasil 2000; c2002 [cited 2006 nov 4].
IBGE Ministério do Planejamento, Orçamento e Gestão [97 pp]. Available from: http://www.ibge.gov.br/home/estatistica/ populacao/perfilidoso/perfidosos2000.pdf

Gontijo ED, Rocha MOC, Oliveira UT 1996. Perfil clínicoepidemiológico de chagásicos atendidos em ambulatório de referência e proposição de modelo de atenção ao chagásico na perspectiva do SUS. Rev Soc Bras Med Trop 29: 101-108.

Guariento ME, Ramos MC, Gontijo JAR, Carvalhal SS 1993. Doença de Chagas e hipertensão arterial primária. Arq Bras Cardiol 60: 71-75.

Ianni BM, Mady C, Arteaga E, Fernandes F 1998. Doenças cardiovasculares observadas durante o seguimento de um grupo de pacientes na forma indeterminada da doença de Chagas. Arq Bras Cardiol 71: 21-24.

Kloetzel K, Dias JCP 1968. Mortality in Chagas disease:life table for the period 1949-1967 in an unselected population. Rev Inst Med Trop São Paulo 10: 5-8.

Lazzari JO, Pereira M, Antunes CMF, Guimarães A, Moncayo A, Dominguez RC, Pieretti OH, Macedo V, Rassi A, Manguire J, Romero AA 1998. Diagnostic electrocardiography in epidemiological studies of Chagas disease: Multicenter evaluation of a standardized method. Rev Panam Salud Publ 4: 317-330.

Macedo AM, Machado CR, Oliveira RP, Pena SD 2004. Trypanosoma cruzi: genetic structure of populations and relevance of genetic variability to the pathogenesis of Chagas disease. Mem Inst Oswaldo Cruz 99: 1-12.

Macedo VO 1973. Influência da exposição à reinfecção na evolução da doença de Chagas (estudo longitudinal de cinco anos), PhD Thesis, Universidade Federal do Rio de Janeiro, $125 \mathrm{pp}$.

Macedo VO 1993. Inquérito eletrocardiográfico nacional para doença de Chagas. Rev Soc Bras Med Trop 26 (Suppl. II): 12-13.

Magalhães HP 1980. Principios de radiologia do coração e dos vasos da base: texto programado, Sarvier, São Paulo, 148 pp.

MS - Ministério da Saúde, Secretaria de vigilância em saúde 2005. Consenso brasileiro em doença de Chagas. Rev Soc Bras Med Trop 38 (Suppl. III): 7-29.

Netto JCA, Mello JV, Barbosa W 1970. Doença de Chagas, correlação sorológica e eletrocardiográfica em grupos de indivíduos idosos. Rev Soc Bras Med Trop 4: 75-82.

Oliveira-Marques DS 2004. Avaliação de pacientes assintomáticos com formas cardíacas iniciais da doença de Chagas, através da análise do eletrocardiograma dinâmico, ecocardiograma e peptídeo natriurético tipo $B$, PhD Thesis, Faculdade de Medicina da Universidade de São Paulo, São Paulo, 122 pp.

Pereira-Barretto AC, Arteaga E, Mady C, Ianni BM, Bellotti G, Pileggi F 1993. Sexo masculino. Fator prognóstico na doença de Chagas. Arq Bras Cardiol 60: 25-27.

Porto CC, Rassi A, Faria GHDC 1985. Aspectos sócioeconômicos e médico-trabalhistas. In: Cançado JR, Chuster M (eds). Cardiopatia Chagásica, Imprensa Oficial, Belo Horizonte, p. 362-366.

Rassi Jr A 2003. Fatores prognósticos na cardiopatia chagásica crônica, PhD Thesis, Faculdade de Medicina da Universidade de São Paulo, São Paulo, 90 pp.

Rezende JM, Lauar KL, Oliveira AR 1960. Aspectos clínicos e 
radiológicos da aperistalsis do esôfago. Rev Bras Gastroenterol 12: 247-262.

Rocha MOC, Correia PC, Barros MVL, Torres RM, Ribeiro ALP, Teixeira MM 2003. Cardiovascular function in elderly patients with chronic chagasic cardiopathy. Rev Soc Bras Med Trop 36 (Suppl. 5): 545-550.

Rouquayrol MZ 1993. Epidemiologia \& Saúde, 4th ed., MEDSI, Rio de Janeiro, 540 pp.

SBC - Sociedade Brasileira de Cardiologia 2004. IV Diretrizes brasileiras de hipertensão arterial. Arq Bras Cardiol 82 (Suppl. IV): 1-14.

Silva AC 1992. Doença de Chagas no paciente idoso. Rev Soc Bras Med Trop 25 (Suppl. III): 69-70.

Teichholz LE, Kreulen T, Herman MV, Gorlin R 1976. Problems in echocardiographic volume determinations: echocardiographic angiographic correlations in the presence or absence of asynergy. Am J Cardiol 37: 7-11.
Uchoa E, Firmo JO, Dias EC, Pereira MS, Gontijo ED 2002. Signs, meanings, and actions associated with Chagas disease. Cad Saúde Públ 18: 71-79.

Ximenes CA, Rezende JM, Moreira H, Vaz MGM 1984. Técnica simplificada para o diagnóstico radiológico do megaesôfago chagásico. Rev Soc Bras Med Trop 17 (Suppl.): 23.

WHO- World Health Organization 2005a . Tropical Disease Research: progress 2003-2004. Special Programme for Research \& Training in Tropical Diseases, Programme Report 17, Geneva, 98 pp.

WHO - World Health Organization 2005b . Envelhecimento ativo: uma política de saúde. Trad. Suzana Gontijo. In Organização Pan-Americana da Saúde, Brasília, 60 pp.

Zicker F 1990. Epidemiology of Chagas heart disease in an urban area in Central Brazil. A population-based study to assess risk factors for cardiopathy, $\mathrm{PhD}$ Thesis, London School of Hygiene and Tropical Medicine, London, 249 pp. 